\author{
돼지 SLA class III 영역 내 C4B 및 BAT2의 cSNP 동정 및 \\ 이를 이용한 유전자형 분석 \\ 김재환* · 임현태* - 서보영* - 이상호** . 이재봉* · 유채경*** . 정은지*** · 전진태* \\ 경상대학교 대학원 응용생명과학부(BK21)*, 경상대학교 학교기업 GAST**, \\ 경상대학교 농생명학부***
}

\title{
cSNP Identification and Genotyping from C4B and BAT2 Assigned to the SLA Class III Region
}

\author{
J. H. Kim*, H. T. Lim*, B. Y. Seo*, S. H. Lee**, J. B. Lee*, C. K. Yoo***, E. J. Jung*** \\ and J. T. Jeon*
}

Division of Applied Life Science(BK21) Graduate School of Gyeongsang National University*, Gyeongnam animal science and technology, Gyeongsang National University**,

Division of Agriculture and Life, Gyeongsang National University***

\begin{abstract}
$C 4 B$ and BAT2, assigned to the SLA class III region, were recently reported on relation with human diseases. The primers for RT-PCR and RACE-PCR for CDS analysis of these genes of pig were designed by aligning the CDSs of humans and mice from GenBank. After we amplified and sequenced with these primers and cDNAs, the full-length CDSs of pig were determined. The CDS lengths of $C 4 B$ and BAT2 were shown as 5226 bp and 6501 bp. In addition, the identities of nucleotide sequences with human and mouse were $76 \%$ to $87 \%$, and the identities of amino acids were $72 \%$ to $90 \%$. After we carried out the alignment with determined CDSs in this study and pig genomic sequences from GenBank, the primers for cSNP detection in genome were designed in intron regions that flanked one or more exons. Then, we amplified and directly sequenced with genomic DNAs of six pig breeds. Four cSNPs from $C 4 B$ and three 3 cSNPs from BAT2 were identified. In addition, amino acid substitution occurred in six cSNP positions except for C4248T of C4B. By the Multiplex-ARMS method, we genotyped seven cSNPs with DNA samples used for direct sequencing. We verified that this result was the same as that analyzed using direct sequencing. To demonstrate recrudescence, we performed both direct sequencing and Multiplex-ARMS on two randomly selected DNA samples. The genotype of each sample showed the same result from both methods. Therefore, seven cSNPs were identified from $C 4 B$ and BAT2 and could be used as the basic data for haplotype analysis of SLA class III region. Moreover, the Multiplex-ARMS method should be powerful for genotyping of genes assigned to the whole SLA region for the xenograft study.
\end{abstract}

(Key words : C4B, BAT2, cSNP, Multiplex-ARMS, Direct sequencing, Genotyping, SLA)

본 연구에서의 변이를 포함하는 염기서열은 GenBank(EU076593, EU076594)에 등록되었음.

Corresponding author: J. T. Jeon, Division of Applied Life Science, Department of Animal Science, Gyeongsang National University, Jinju 660-701, Gyeongnam, Korea.

Tel : 055-751-5516, Fax : 055-756-7171, E-mail : jtjeon@gnu.ac.kr 


\section{I. 서 론}

최근 들어 인간의 장기를 대체하기 위한 동 물로서 돼지의 중요성이 높아지고 있다. 특히, 미니돼지는 크기와 생리적인 면에서 사람과 유 사하다는 장점을 가지고 있기 때문에 장기이식 분야에서 잠재적 공여동물로서 높은 가능성을 제시하고 있다(Sachs, 1994; Chen 등, 2004).

주조직적합성복합체 (major histocompatibility complex; MHC)는 세포 상호작용 및 자신과 비 자신의 구별에 중요한 역할을 하는 연관된 유 전자들의 집합으로서, 항원을 이식하는 $\mathrm{T}$-세포 의 면역반응에 있어서 매우 중요하게 작용한다 (Rothbard와 Gefter, 1991; Ierino 등, 1999). 돼지 의 $\mathrm{MHC}$ 는 swine leukocyte antigen (SLA)으로 알려져 있는데, 이들에 의한 면역반응의 이해 와 철저한 육종체계에 의한 동일한 유전형질을 갖는 순종 혈통을 구축하기 위해서는 SLA 영 역에 대한 세부적인 연구가 필요하며, 이와 관 련하여 많은 연구들이 진행되어 왔다 (Sachs 등, 1976; Wu 등, 2004; Lee 등, 2005; O’Connell 등, 2005). 특히, 이 영역 내부에 존재하는 유전 자들 각각에 대한 다형성 및 haplotype 분석은 이종장기의 이식을 위한 순종혈통을 구축하는 데 있어서 가장 필수적인 과정이다 (Cascalho와 Platt, 2001; Martens 등, 2003). 돼지 SLA 영역 은 돼지 7번 염색체 내 class I, II, III 등 세 구 역으로 구분되며, 특히 class III은 p arm의 동 원체 부위에 위치하고 있다(Geffrotin 등, 1984; Smith 등, 2005). 이 영역은 약 $700 \mathrm{~kb}$ 정도로 확장되어 있으며 다양한 기능을 갖는 단백질을 암호화하는 약 60 개의 유전자가 존재하고 있다 (Renard 등, 2006). 또한 사람과 마우스의 class III 영역의 비교 결과 매우 유사한 구조를 갖는 것으로 확인되어 진화과정에서 매우 잘 보존되 어 있는 영역으로 알려져 있다(Chardon 등, 1999). 비록 현재까지 사람의 질병에 대해서 class I 및 II 영역 내에 존재하는 유전자들에 대한 연구가 많이 진행되었지만, 최근 들어 class III 영역 역시 질병과의 연관성에 대한 연 구가 보고 되면서 이 영역에 대한 관심이 점점 높아지고 있다 (Schroeder 등, 1998; Okamoto 등,
2003; Shichi 등, 2005). 하지만 사람과 마우스를 제외하면 돼지를 포함한 다른 포유류에서는 MHC 영역에 대한 연구가 폭넓게 이루어지지 않았으며, 특히 class III 영역에 관한 연구는 더 더욱 미비한 실정이다.

SLA class III 영역 내 존재하는 유전자들 중 C4B(complement component 4B)와 BAT2 (HLA-B associated transcript 2)는 $\mathrm{CDS}$ 및 아미노산 서 열이 다른 유전자들에 비해 가장 길게 나타나 며, 최근 들어 두 유전자와 사람의 질병과의 연관성이 보고되고 있어 이들 유전자들에 대한 중요성이 높아지고 있다 (Martinez 등, 2004; Blaskó 등, 2007; Tsuda 등, 2007). 따라서 본 연 구는 SLA class III 영역 내 C4B및 BAT2의 coding region에서 나타나는 $\mathrm{cSNP}$ 를 동정하고, Multiplex-Amplification Refractory Mutation System (ARMS) 방법을 이용하여 동정된 cSNP에 대한 유전자형을 분석하고자 실시하였다.

\section{ㅍ. 재료 및 방법}

\section{Genomic DNA 및 RNA 추출 및 cDNA 합성}

RNA 추출은 Trizol (Gibco BRL, USA)을 사용 하였으며, mRNA는 PolyATtract mRNA Isolation Systems (Promega, USA)를 사용하여 정제하였 다. 또한 cDNA 합성은 Smart ${ }^{\mathrm{TM}}$ Rapid Amplification of cDNA Ends (RACE) Kit (Clontech, $\mathrm{USA}$ )을 사용하여 실시하였다. 돼지 6품종 (Landrace, Large White, Duroc, Berkshire, Korean native pig, Miniature pig)의 genomic DNA는 Wizard Genomic DNA Purification Kit (Promega, USA)를 이용하여 혈액으로부터 추출하였다.

\section{RT-PCR}

CLUSTAL W program을 사용하여 사람(GenBank accession no. NM_001002029, NM_080686) 과 마우스(GenBank accession no. NM_009780, NM_020027)로부터 보고된 두 유전자의 CDS를 이용하여 alignment를 실시하였다. CDS를 증폭 
하기 위한 primer는 두 유전자 각각 3 개의 영역 으로 나누어 염기상동성이 높은 부분에서 $3 \mathrm{set}$ 의 primer를 서로 overlapping 되게 제작하였으 며, nested PCR를 위한 primer를 포함하여 각 영역 당 두 set의 primer를 제작하였다. 1차 PCR 반응은 1st cDNA $25 \mathrm{ng}$, Taq polymerase 1.5 unit (TaKaRa, Japan), $10 \times$ buffer $2.5 \mu \ell, 0.2$ $\mathrm{mM}$ dNTP, $1.5 \mathrm{mM} \mathrm{MgCl}$, 10 pmol primer 각 각 $1.5 \mu \ell$ 그리고 증류수 $13.7 \mu \ell$ 를 첨가하여 최종 $25 \mu \ell$ 로 반응하였다. Nested PCR 반응은 1 차 PCR product $1 \mu \ell$ 를 주형으로 첨가하였으 며, 나머지 조건은 1 차 $\mathrm{PCR}$ 조건과 동일하게 수행하였다. 1차 PCR 및 nested PCR 반응조건 은 동일하며 다음과 같이 수행하였다. $94^{\circ} \mathrm{C}$ 에 서 2 분간 변성시킨 후 $94^{\circ} \mathrm{C}$ 에서 1 분, $55^{\circ} \mathrm{C}$ 에서 1 분, $72^{\circ} \mathrm{C}$ 에서 2 분을 1 cycle로 하여 35 회 반복 하였다. 그 후 $72^{\circ} \mathrm{C}$ 에서 5분간 신장시킨 후 $4{ }^{\circ} \mathrm{C}$ 에서 종료하였다. PCR product는 $1.5 \%$ agarose gel에서 전기영동한 후 ethidium bromide로 염색 하여 사람 및 마우스에 대응되는 크기의 절편 만을 회수하여 QIAEX II Gel Extraction Kit (Quagen, USA)로 정제하였다. 그 후 TOPO TA Cloning Kit(Invitrogen, USA)을 사용하여 cloning 한 후 Applied Biosystems 3700 DNA sequencer (PE Applied Biosystems, USA)로 염기서열을 결 정하였다.

\section{RACE-PCR}

5' 및 3' UTR (untranslated region) 서열을 포 함한 mRNA 전체 서열을 확인하기 위해서 SMART
RACE cDNA Amplification Kit (Clontech, USA) 를 이용하여 5' 및 3' RACE를 수행하였으며, 주어진 protocol을 일부 변형하여 사용하였다. 이를 위해서 RT-PCR에 의해 분석된 염기서열 을 기초로 primer를 제작하였다(Table 1). 1차 RACE-PCR 반응은 합성된 CDNA $5 \mu$, Taq polymerase 2.5 unit (TaKaRa, Japan), $10 \times$ buffer $5 \mu \ell, 0.2 \mathrm{mM}$ dNTP, $1.5 \mathrm{mM} \mathrm{MgCl}_{2}$, RACE-5'-1 (10 pmol) primer 혹은 RACE-3'-1 (10 pmol) primer 각각 $2 \mu \ell, \mathrm{UPM}(10 \times) 5 \mu \ell$ 그리고 증류 수 $28.7 \mu \ell$ 를 첨가하여 최종 $50 \mu \ell$ 로 반응하였 다. 2차 RACE-PCR 반응은 1차 PCR product 3 $\mu \ell$ 에 Taq polymerase 2.5 unit (TaKaRa, Japan), $10 \times$ buffer $5 \mu \ell, 0.2 \mathrm{mM}$ dNTP, $1.5 \mathrm{mM} \mathrm{MgCl}_{2}$, RACE-5'-2 (10 pmol) primer 혹은 RACE-3'-2 (10 pmol) primer 각각 $3 \mu \ell$, NUP $2 \mu \ell$ 그리고 증류 수 $32.7 \mu \ell$ 를 첨가하여 최종 $50 \mu \ell$ 로 수행하였 다. 1차 및 2차 PCR 반응조건은 동일하게 수행 하였으며 다음과 같다. $94^{\circ} \mathrm{C}$ 에서 2 분간 변성시 킨 후 $94^{\circ} \mathrm{C}$ 에서 30 초, $60^{\circ} \mathrm{C}$ 에서 1 분, $72{ }^{\circ} \mathrm{C}$ 에서 1 분 30 초를 1 cycle로 하여 35회 반복하였다. 그 후 $72^{\circ} \mathrm{C}$ 에서 5 분간 신장시킨 후 $4^{\circ} \mathrm{C}$ 에서 종 료하였다. 증폭된 PCR product는 QIAEX II Gel Extraction Kit(Qiagen, USA)로 정제하여 염기서 열 결정에 사용하였다.

\section{Exon 영역을 위한 primer 제작 및 증폭}

CLUSTAL W program을 사용하여 앞서 결정 된 $\mathrm{C} 4 \mathrm{~B}$ 및 $\mathrm{BAT2}$ 의 전체 $\mathrm{CDS}$ 와 돼지 $\mathrm{SLA}$ class III 영역의 genomic sequence(GenBank

Table 1. Primer sequences used for amplification of porcine $C 4 B$ and BAT2 in this study

\begin{tabular}{cccl}
\hline Gene name & Analysis method & Primer name & \multicolumn{1}{c}{ Primer sequence(5'-3') } \\
\hline \hline C4B & 5' RACE-PCR & RACE-5'-1 & AACACCGATCCTGTCACCACCTGTC \\
& & RACE-5'-2 & GAACAGGAGCAACCTGGGCTTCTG \\
& \multirow{2}{*}{ 3' RACE-PCR } & RACE-3'-1 & TCTGATCATGGGCCTGGACGGGAC \\
& & RACE-3'-2 & CTCGAACTGCTGGATCGAGGAGATG \\
\hline \multirow{2}{*}{ BAT2 } & 5' RACE-PCR & RACE-5'-1 & AGCAACTTTCCGGGACTCTGCAG \\
& \multirow{2}{*}{ 3' RACE-PCR } & RACE-5'-2 & TCTGGATCTCTAAGGACTTGCCC \\
& & RACE-3'-1 & TCTGGCCTCAATTCCCGTCTCAAGG \\
& & ACCATCTCGAGAAGGGCCATCCCGAA \\
\hline
\end{tabular}


accession no. AL773560, BX548169)를 alignment 하여 genome 상의 exon/intron 영역을 결정하였 다. 결정된 각각의 exon 영역을 증폭하기 위한 primer는 $C 4 B$ 및 $B A T 2$ 각각 17 set 및 19 set을 제작하였으며, 하나 이상의 exon이 포함되게 하여 양 말단의 intron에서 제작되었다. Exon 영역의 증폭을 위하여 돼지 6품종을 사용하였 으며, 이 때 각 품종별로 나타날 수 있는 cSNP 의 정확한 확인을 위하여 각 품종별로 5 개체 의 genomic DNA을 혼합하여 template로 사용하 였다. PCR 반응은 Taq polymerase 1.5 unit (Genet Bio, Korea), 10×buffer $2.5 \mu \ell, 0.2 \mathrm{mM}$ dNTP, $1.5 \mathrm{mM} \mathrm{MgCl} 2,10 \mathrm{pmol}$ primer 각각 1.5 $\mu \ell$, genomic DNA 각각 $2 \mu \ell$, 그리고 증류수 $13.7 \mu \ell$ 를 첨가하여 최종 $25 \mu \ell$ 로 반응하였다. PCR 반응조건은 $94^{\circ} \mathrm{C}$ 에서 2분간 변성시킨 후 $94^{\circ} \mathrm{C}$ 에서 30 초, $55 \sim 65^{\circ} \mathrm{C}$ 에서 45 초, $72^{\circ} \mathrm{C}$ 에서 60 초를 1 cycle로 하여 35회 반복 수행하였으며, $72^{\circ} \mathrm{C}$ 에서 5 분간 신장시킨 후 $4^{\circ} \mathrm{C}$ 에서 종료하였 다. PCR product는 $1.5 \%$ agarose gel에서 전기 영동한 후 ethidium bromide로 염색하여 확인하 였다.

\section{Direct sequencing 및 $\mathrm{CSNP}$ 동정}

증폭된 PCR 산물은 $\mathrm{GELase}^{\mathrm{TM}}$ Agarose GelDigesting Preparation(Epicentre, USA)을 사용하 여 gel정제를 실시하였으며, Applied Biosystems 3700 DNA sequencer (PE Applied Biosystems, USA)를 이용하여 direct sequencing을 실시하였 다. 결정된 염기서열은 Sequencher ver. 4.6 (Gene codes, USA)을 사용하여 6품종 사이에서 나타나는 $\mathrm{cSNP}$ 를 확인하였다.

\section{Multiplex-ARMS를 위한 primer 제작 및 유전자형 분석}

확인된 $\mathrm{cSNP}$ 를 대상으로 ARMS 방법을 사용 하여 primer를 제작하였다 (Table 4). 이 때 하나 의 SNP에서 나타나는 두 allele를 확인하기 위 해서 ARMS 방법에 따라 3' 말단의 첫째 염기 가 mismatching된 두 개의 reverse primer를 제
작하였으며, 5' 방향에 $\mathrm{T}$ 염기의 추가로 분석 후 두 allele을 구분할 수 있게 하였다. 또한 multiplex PCR에 의한 유전자형 분석을 위해서 각각의 forward primer는 FAM, PET, NED, VIC 을 이용하여 형광표지를 실시하였다. Multiplex PCR 반응은 주형 DNA $0.04 \mu \mathrm{g}, \mathrm{H}-\mathrm{Taq}$ DNA polymerase 1.5 unit (Bioneer, Korea), $10 \times$ buffer $1.5 \mu \ell, 0.25 \mathrm{mM}$ dNTP, primer를 첨가한 후 3 차 증류수를 첨가하여 최종 $15 \mu$ 로 반응하였다. 이 때 primer의 농도는 최적의 반응을 위해서 primer set에 따라 0.4-8 $\mu \mathrm{m}$ 로 첨가하였다. PCR 조건은 touch-down PCR 방법을 사용하여 $95^{\circ} \mathrm{C}$ 에서 15 분간 변성시킨 후 $94^{\circ} \mathrm{C}$ 에서 60 초, $63^{\circ} \mathrm{C}$ 에서 75 초, $72^{\circ} \mathrm{C}$ 에 60 초를 5 회 반복, $94^{\circ} \mathrm{C}$ 에서 60 초, $62^{\circ} \mathrm{C}$ 에서 75 초, $72^{\circ} \mathrm{C}$ 에 60 초를 5 회 반복, $94{ }^{\circ} \mathrm{C}$ 에서 60 초, $61^{\circ} \mathrm{C}$ 에서 75 초, $72^{\circ} \mathrm{C}$ 에 60 초를 20 회 반복, $94^{\circ} \mathrm{C}$ 에서 60 초, $60^{\circ} \mathrm{C}$ 에서 75 초, 72 ${ }^{\circ} \mathrm{C}$ 에 60 초를 10 회 반복하여 수행하였다. 그 후 $65^{\circ} \mathrm{C}$ 에서 30 분간 처리 후 $8^{\circ} \mathrm{C}$ 에서 종료하였다. PCR product는 Applied Biosystems 3700 DNA sequencer (PE Applied Biosystems, USA)를 이용 하여 전기영동을 실시한 후 GenScan version 2.1(Applied Biosystems, USA)로 유전자형을 확 인하였다.

\section{Multiplex-ARMS와 direct sequencing 결 과와의 blind test}

결과의 정확성을 재확인하기 위하여 무작위 로 두 개의 DNA 시료를 선택하여 direct sequencing에 의한 염기서열 분석과 Multiplex-ARMS 에 의한 유전자형 분석을 동시에 실시하여 두 결과를 비교하였다.

\section{피. 결과 및 고찰}

\section{1. $C 4 B$ 및 BAT2}

사람과 마우스에서는 C4 locus에 C4A(complement component $4 A$ )와 $C 4 B$ 등 2개의 유전자가 존재하는데, 이들에 의해 합성되는 두 단백질 은 항원-항체 복합체와 보체구성체들과의 상호 
작용에 관여한다(Xie 등, 2003; Robins 등, 2007). 또한 이들 유전자들의 결손에 의해서 신 장의 홍반성루푸스 (lupus erythematosus)에 영향 을 주는 것으로 보고 되었다(Yang 등, 2004; Ittiprasert 등, 2005). 반면에 돼지에서는 $C 4 A$ 와 $C 4 B$ 중 하나만 나타나는데 (Renard 등, 2006), 이런 결과로서 사람의 두 유전자의 기능이 돼 지에서는 하나의 유전자에 의해서 이루어진다 고 예상할 수 있다. BAT2에 대한 연구는 상대 적으로 미비하지만, 전사조절단백질과 유사한 반복적인 proline-rich 구조를 나타내며, 인슐린 의존성 당뇨병 (insulin-dependent diabetes)의 발 생과정에서 췌장의 베타 세포의 염증과정에 관 여할 것으로 추정하고 있다 (Banerji 등, 1990). 특히, 류마티스관절염 (rheumatoid arthritis)에 대 한 후보유전자로 인식되고 있다 (Hashimoto 등, 1999).

\section{2. 돼지 $C 4 B$ 및 $B A T 2$ 의 $\mathrm{CDS}$ 결정}

RT-PCR 및 RACE-PCR에 의해서 돼지 $C 4 B$ 및 $B A T 2$ 의 $\mathrm{CDS}$ 를 포함한 전체 mRNA 서열을 분석하였으며, 각각 GenBank database에 등록하 였다(C4B, GenBank accession no. EU076594; BAT2, GenBank accession no. EU076593). 사람 의 $C 4 B$ (GenBank accession no. NC_000006, NM_001002029) 및 BAT2 (GenBank accession no. NC_000006, NM_080686)는 각각 41개, 31개의 exon으로 구성되어 있으며, $C 4 B$ 인 경우 1 번 exon에 개시코돈이 존재하는 반면 BAT2는 2번 exon에 존재한다. 또한 $\mathrm{CDS}$ 의 전체길이는 두 유전자 각각 5235 bp 및 6474 bp로 보고되어 있다. 본 연구에서 분석된 두 유전자의 $\mathrm{CDS}$ 의 길이는 Table 2에 제시된 바와 같이 각각 5226 $\mathrm{bp}$ 및 $6501 \mathrm{bp}$ 로, 사람과 비교한 결과 $C 4 B$ 인 경우 $9 \mathrm{bp}$ 의 결실이 확인된 반면 $B A T 2$ 는 27 $\mathrm{bp}$ 가 삽입되었음을 확인하였다. 그러나 이러한 결실 및 삽입에 의해서 아미노산 해독틀은 변 화하지 않았다. 또한 분석된 돼지 $\mathrm{CDS}$ 와 앞서 보고된 genomic sequence (GenBank accession no. AL773560, BX548169)와 alignment를 실시한 결 과 돼지 $C 4 B$ 및 $B A T 2$ 는 각각 41 개와 31 개의 exon으로 구성되어 있고, 두 유전자 각각 사람 과 동일한 exon에 개시코돈이 존재하였다.

분석된 돼지 $\mathrm{C} 4 \mathrm{~B}$ 와 $\mathrm{BAT2}$ 의 $\mathrm{CDS}$ 와 아미노산 서열을 사람 및 마우스와 비교하였다 (Table 2). 그 결과 $C 4 B$ 인 경우 $\mathrm{CDS}$ 는 사람과 $84 \%$, 마우 스와는 $76 \%$ 의 상동성을 보였으며, 아미노산 서 열은 사람과 마우스 각각 $80 \%, 72 \%$ 의 상동성 을 보였다. BAT2의 CDS는 $88 \%, 87 \%$ 로 확인되 었으며, 아미노산 서열은 $87 \%, 89 \%$ 로 나타나 $C 4 B$ 에 비해서 다소 높은 상동성을 보였다.

\section{3. 품종별 CSNP 동정}

분석된 두 유전자의 CDS와 앞서 보도된 genomic sequence를 대상으로 alignment를 실시 하여 exon/intron 영역을 결정하고 이를 바탕으 로 exon 영역을 증폭할 수 있는 primer를 제작 하였다. 이를 사용하여 돼지 6품종을 대상으로 증폭한 후 direct sequencing을 통한 genome 상 에서의 $\mathrm{CSNP}$ 를 분석한 결과 $\mathrm{C} 4 \mathrm{~B}$ 에서 4 개 (G17T, C316T, A1556G, A4248C)가, BAT2에서 3 개 $(C 1094 G, C 1832 T, A 2059 G)$ 의 cSNP가 동정되 었다(Fig. 1, Table 3). Yorkshire와 Duroc에서는 모두 homo-type으로 나타났으며, Landrace와 Berkshire에서는 BAT2의 1094번째와 2059번째 에서만 hetero-type이 나타나는 것을 확인하였 다. 반면에 $\mathrm{KNP}$ 와 Miniature pig에서는 각각 3 개의 hetero-type이 발생하였는데, $\mathrm{KNP}$ 에서 나 타난 BAT2의 1094번째를 제외하면 나머지 품 종들과 서로 상이한 위치에서 발생하였다. 또한

Table 2. Length of CDS and identity with human and mouse of C4B and BAT2

\begin{tabular}{ccccc}
\hline \multirow{2}{*}{ Gene name } & Description & Length of CDS & \multicolumn{2}{c}{ Identity with human/mouse(\%) } \\
\cline { 3 - 5 } & & & Nucleotide & Amino acid \\
\hline \hline C4B & Complement component $4 B$ & 5226 bp & $84 / 76$ & $80 / 72$ \\
BAT2 & $H L A-B$ associated transcript 2 & 6501 bp & $88 / 87$ & $90 / 89$ \\
\hline
\end{tabular}




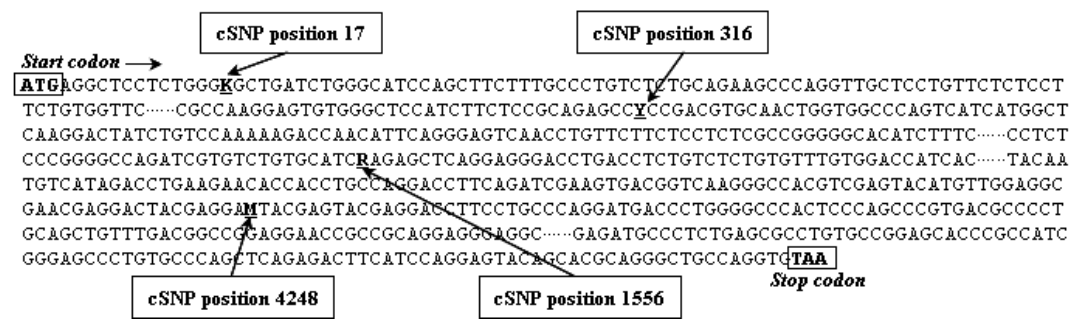

(A)

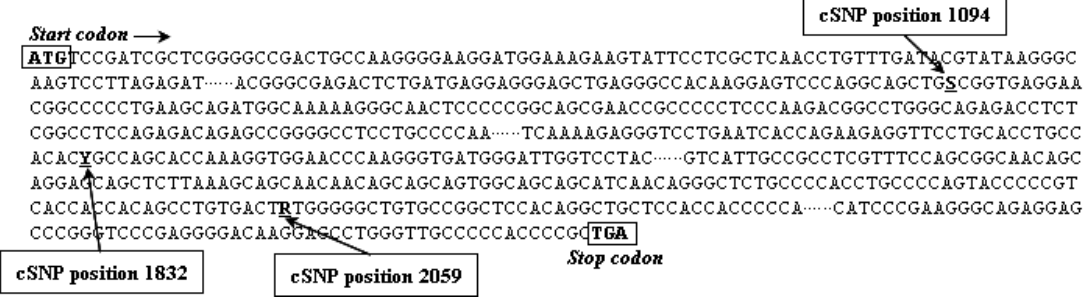

(B)

Fig. 1. The positions of cSNPs identified from $C 4 B(A)$ and $B A T 2(B)$ of pig. $K, Y, R, M$, and $\mathrm{S}$ indicated as $\mathrm{G}$ or $\mathrm{T}, \mathrm{C}$ or $\mathrm{T}, \mathrm{A}$ or $\mathrm{G}, \mathrm{A}$ or $\mathrm{C}$, and $\mathrm{C}$ or $\mathrm{G}$, respectively. The bold and boxed letters were start and stop codons. The dots denote the abbreviation of nucleotide sequences.

Table 3. Information of cSNPs identified from $C 4 B$ and BAT2 among six pig breeds

\begin{tabular}{|c|c|c|c|c|c|c|c|c|}
\hline \multirow{2}{*}{$\begin{array}{l}\text { Gene } \\
\text { name }\end{array}$} & \multirow{2}{*}{$\begin{array}{l}\text { Position of } \\
\text { nucleotide }\end{array}$} & \multicolumn{6}{|c|}{ Pig breeds ${ }^{1)}$} & \multirow{2}{*}{$\begin{array}{l}\text { Position of } \\
\text { amino acid }\end{array}$} \\
\hline & & $\mathrm{L}$ & $\mathrm{Y}$ & $\mathrm{D}$ & B & KNP & $\mathrm{M}$ & \\
\hline \multirow[t]{4}{*}{$C 4 B$} & G17T & $\mathrm{T}$ & $\mathrm{T}$ & $\mathrm{T}$ & $\mathrm{T}$ & G/T & $\mathrm{T}$ & G6V \\
\hline & C316T & $\mathrm{C}$ & $\mathrm{C}$ & $\mathrm{C}$ & $\mathrm{C}$ & $\mathrm{C} / \mathrm{T}$ & $\mathrm{C}$ & P106S \\
\hline & A1556G & G & G & G & G & G & $\mathrm{A} / \mathrm{G}$ & Q519R \\
\hline & A4248C & $\mathrm{C}$ & $\mathrm{C}$ & $\mathrm{C}$ & $\mathrm{C}$ & $\mathrm{C}$ & $\mathrm{A} / \mathrm{C}$ & - \\
\hline \multirow[t]{3}{*}{ BAT2 } & C1094G & $\mathrm{G} / \mathrm{C}$ & $\mathrm{C}$ & $\mathrm{C}$ & $\mathrm{G} / \mathrm{C}$ & $\mathrm{G} / \mathrm{C}$ & $\mathrm{C}$ & A365G \\
\hline & C1832T & $\mathrm{C}$ & $\mathrm{C}$ & $\mathrm{C}$ & $\mathrm{C}$ & $\mathrm{C}$ & $\mathrm{C} / \mathrm{T}$ & P611L \\
\hline & A2059G & $\mathrm{A} / \mathrm{G}$ & A & A & $\mathrm{A} / \mathrm{G}$ & A & A & M687V \\
\hline
\end{tabular}

1) L, Landrace; Y, Yorkshire; D, Duroc; B, Berkshire; KNP, Korean native pig; M, Miniature pig

7개의 cSNP에 의해 아미노산치환이 발생하는 지를 알아보기 위해 translation을 실시한 결과 $C 4 B$ 의 $A 4248 C$ 를 제외한 나머지 모든 $\mathrm{CSNP}$ 에 의해서 아미노산 치환이 발생하였다.

\section{Multiplex-ARMS에 의한 유전자형 분석}

Multiplex-ARMS 방법은 각 SNP에 대해서 두 allele 중 target allele에는 결합하고 다른 allele 에는 결합하지 않도록 제작된 두 개의 allele- specific reverse primer와 형광표지된 forward primer를 사용하여 유전자형을 분석하는 기법 으로서 하나 혹은 여러 개의 SNP에 대한 유전 자형을 분석할 수 있는 기법이다. 이 기법은 빠르고 상대적으로 저렴하고 간편하다는 장점 이 있기 때문에 최근 들어 유전자형 분석에 많 이 사용되고 있다(Balbi 등, 2007; Lacerra 등, 2007; Taylor 등, 2007).

돼지 $\mathrm{C} 4 \mathrm{~B}$ 및 $\mathrm{BAT2}$ 에서 동정된 7 개의 $\mathrm{CSNP}$ 를 대상으로 Multiplex-ARMS 방법을 위한 primer 
를 제작한 후 SNP 동정에 사용한 품종별 하나 의 DNA sample를 사용하여 유전자형 분석을 실시하였다. 그 결과 Table 3에 제시된 각 품종 별 유전자형과 동일한 결과를 얻을 수 있다. 이런 결과를 재확인하기 위해서 모든 품종을 대상으로 무작위로 2개의 genomic DNA을 선발 하여 direct sequencing과 Multiplex-ARMS 방법 을 이용하여 유전자형을 분석하고 비교하였다. 그 결과 Fig. 2와 같이 두 분석결과가 일치됨을 확인하였다.

\section{SLA 영역에 대한 효율적인 유전형 분석 및 방법}

인간의 장기를 대체하기 위한 동물모델로서 돼지의 중요성이 높아지고 있으며, 이에 따라 돼지의 순종혈통을 구축하는 것이 필수적이다. 이를 위해서는 돼지 SLA 영역 내 존재하는 유 전자들의 polymorphism 및 haplotype 분석이 반 드시 이루어져야 하며, 이를 위해서는 순종혈 통 구축과정에서 각각의 개체들의 haplotype 등 을 간편하고 효율적으로 분석할 수 있는 방법
이 필요하다. 최근에 보고된 많은 연구결과들 은 PCR-RFLP나 PCR-ssp 혹은 이 두 방법을 혼 용하여 SLA 영역의 유전자들에 대한 haplotype을 분석하고 있다. 이 중 PCR-RFLP는 하나 의 시료 $\mathrm{DNA}$ 를 사용하여 단지 하나의 $\mathrm{SNP}$ 에 대한 유전자형만을 확인할 수 있으며, 각각의 제한효소마다 인지부위 특이성을 가지고 있기 때문에 각각의 SNP에 대해서 제한효소 인지부 위가 존재하지 않을 가능성도 배제할 수 없다. 본 연구에서 사용한 Multiplex-ARMS 방법은 여 러 개의 SNP를 대상으로 각 allele에 대한 서로 다른 primer를 제작하여 증폭 및 전기영동 후 대상 SNP에 대한 유전자형을 한번에 확인할 수 있는 방법으로 PCR-ssp 보다는 좀 더 간편 하고 효율적인 방법이라고 사료된다.

본 연구에서는 direct sequencing에 의해 $C 4 B$ 와 $\mathrm{BAT} 2$ 로부터 7 개의 $\mathrm{CSNP}$ 를 동정하였다. 또 한 Multiplex-ARMS 방법을 이용하여 이들에 대 한 유전자형을 손쉽게 분석하였으며, 그 결과 는 direct sequencing에 의해 확인된 결과와 일 치하였다. 본 연구에서 동정된 7 개의 $\mathrm{CSNP}$ 는 SLA class III 지역의 haplotype 분석을 위한 기

Table 4. The sequence and information of analysis

\begin{tabular}{|c|c|c|c|c|c|}
\hline $\begin{array}{l}\text { Gene } \\
\text { name }\end{array}$ & $\begin{array}{l}\text { cSNP } \\
\text { position }\end{array}$ & $\begin{array}{l}\text { Forward primer } \\
\qquad\left(5^{\prime}-3^{\prime}\right)\end{array}$ & $\begin{array}{l}\text { Reverse primer }{ }^{1)} \\
\quad\left(5^{\prime}-3^{\prime}\right)\end{array}$ & $\begin{array}{l}\text { Primer } \\
\text { con. }(\mu \mathrm{m})\end{array}$ & $\begin{array}{l}\text { Product } \\
\text { size(bp) }\end{array}$ \\
\hline \multirow[t]{4}{*}{$C 4 B$} & 17 & $\begin{array}{c}\text { TCTAGCATCCTGCTTCCAGG } \\
\text { (PET) }\end{array}$ & $\begin{array}{r}\text { TTTTGCCATGAGGCTCCTCTGGAG } \\
\text { GCCATGAGGCTCCTCTGGAT }\end{array}$ & 0.7 & $\begin{array}{l}90 \\
94\end{array}$ \\
\hline & 316 & $\begin{array}{l}\text { GCTGGTCAGTCTGCAGAAAG } \\
\text { (FAM) }\end{array}$ & $\begin{array}{r}\text { TTTTTTTTTССАТСTTCTCCGCAGAGCAC } \\
\text { TTTTTTCСАTCTTCTCCGCAGAGCAT }\end{array}$ & 0.7 & $\begin{array}{l}155 \\
152\end{array}$ \\
\hline & 1556 & $\begin{array}{c}\text { CTTCTCTGAACCTGCTAACG } \\
\text { (VIC) }\end{array}$ & $\begin{array}{r}\text { TTTTCAGATCGTGTCTGTGCATAG } \\
\text { CAGATCGTGTCTGTGCATAA }\end{array}$ & 8 & $\begin{array}{l}219 \\
215\end{array}$ \\
\hline & 4248 & $\begin{array}{l}\text { ATGCACACGGTGTACTGCAC } \\
(\mathrm{PET})\end{array}$ & $\begin{array}{r}\text { TTTTCGAACGAGGACTACGAGGGC } \\
\text { CGAACGAGGACTACGAGGGA }\end{array}$ & 0.5 & $\begin{array}{l}182 \\
178\end{array}$ \\
\hline \multirow[t]{3}{*}{ BAT2 } & 1094 & $\begin{array}{l}\text { CCTCTAGTACTGCTGCTTCA } \\
\text { (FAM) }\end{array}$ & $\begin{array}{r}\text { TTTTAAGGAGTCCCAGGCAGCTAC } \\
\text { AAGGAGTCCCAGGCAGCTAG }\end{array}$ & 5 & $\begin{array}{l}303 \\
299\end{array}$ \\
\hline & 1832 & $\begin{array}{l}\text { AGGCAGAACTGGTAGAACAC } \\
\text { (NED) }\end{array}$ & $\begin{array}{r}\text { TTTTGTTCCTGCACCTGCCACAAC } \\
\text { GTTCCTGCACCTGCСАCAAT }\end{array}$ & 0.4 & $\begin{array}{l}242 \\
238\end{array}$ \\
\hline & 2059 & $\begin{array}{l}\text { GGAGGAATCATCATCCATCG } \\
\text { (NED) }\end{array}$ & $\begin{array}{r}\text { TTTTACCACCACAGCCTGTGACGG } \\
\text { ACCACCACAGCCTGTGACGA }\end{array}$ & 4 & $\begin{array}{l}148 \\
144\end{array}$ \\
\hline
\end{tabular}

\footnotetext{
${ }^{1)}$ Two reverse primers for each cSNP were designed by ARMS method. For distinguishing of each fragment after genotyping by Multiplex-ARMS method, T nucleotides were inserted in the 3 ' end of reverse primers.
} 


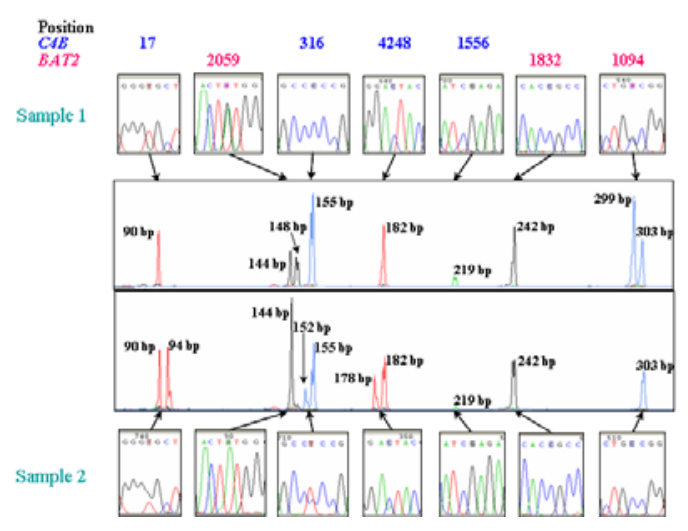

Fig. 2. The result of genotyping based on seven cSNPs from $C 4 B$ and $B A T 2$ with two random samples (sample 1 and sample 2). The upper and lower boxes indicate direct sequencing results of sample 1 and 2 . The number above the upper box indicates each cSNP position. Multiplex-ARMS results are presented in between the two sequencing results. The size of amplified fragment is described above the corresponding peak. The genotypes of seven cSNPs analyzed using Multiplex-ARMS method were the same as those analyzed using direct sequencing.

초자료로 사용될 수 있으며, Multiplex-ARMS 기법은 이종장기 개발에 필수적인 SLA 전체 영역 내 유전자들의 유전자형 분석을 위한 효 율적인 분석방법이라고 사료된다.

$$
\text { IV. 요 약 }
$$

C4B 및 BAT2는 SLA class III 영역에 존재하 며, 최근 들어 사람의 질병과의 연관성이 보고 되고 있다. GenBank database로부터 수집된 사 람과 마우스의 $\mathrm{C} 4 \mathrm{~B}$ 및 $\mathrm{BAT2}$ 의 $\mathrm{CDS}$ 를 염기정 렬하여 상동성이 높은 부분에서 primer를 제작 한 후 RT-PCR 및 RACE-PCR을 수행하여 돼지 $C 4 B$ 및 $B A T 2$ 유전자의 $\mathrm{CDS}$ 서열을 결정하였 다. 염기서열이 결정된 돼지 $C 4 B$ 와 $B A T 2$ 의 $\mathrm{CDS}$ 길이가 각각 $5226 \mathrm{bp}$ 와 $6501 \mathrm{bp}$ 로 나타났
다. 이들 각각의 $\mathrm{CDS}$ 및 아미노산 서열을 사람 및 마우스와 비교한 결과 CDS는 76 87\%, 아미 노산 서열은 $72 \sim 90 \%$ 의 상동성을 보였으며, $C 4 B$ 가 $B A T 2$ 에 비해 다소 낮게 나타났다. 두 유전자에서 나타나는 $\mathrm{cSNP}$ 를 분석하기 위해서 exon 영역을 증폭하기 위한 primer를 제작하였 으며, 돼지 6품종을 대상으로 direct sequencing 을 실시하였다. 그 결과 $C 4 B$ 로부터 4 개, $B A T 2$ 로부터 3 개의 $\mathrm{cSNP}$ 가 확인되었다. 또한 7 개의 $\mathrm{CSNP}$ 중 $\mathrm{C} 4 \mathrm{~B}$ 의 $\mathrm{C} 4248 \mathrm{~T}$ 를 제외한 6 개의 $\mathrm{CSNP}$ 에 의해서 아미노산 치환이 발생하였다. 동일 한 DNA를 사용하여 7개의 $\mathrm{CSNP}$ 를 대상으로 Multiplex-ARMS 방법을 사용하여 유전자형 분 석을 실시한 결과 direct sequencing 결과와 일 치하였다. Multiplex-ARMS 방법의 재현성을 재 확인하기 위해 무작위로 2개의 DNA 시료를 선 택하여 direct sequencing과 Multiplex-ARMS 분 석을 실시하여 유전자형이 일치함을 다시 확인 하였다. 따라서 본 연구에서 확인된 7 개의 cSNP는 SLA class III 지역의 haplotype 분석을 위한 기초 자료로 사용될 수 있으며, Multiplex$\mathrm{ARMS}$ 기법은 이종장기 개발에 필수적인 SLA 전체 영역 내 유전자들의 유전자형 분석을 위 한 효율적인 분석방법이라고 사료된다.

$$
\text { V. 사 사 }
$$

본 연구는 농촌진흥청 ‘바이오그린 21사업 (바 이오장기 : 20070401-034-029-007-03-0)의 지원에 의해 이루어진 연구결과의 일부이며 연구비 지 원에 감사드립니다. 김재환, 임현태, 서보영, 이 재봉은 교육인적자원부 제2단계 BK21 사업의 장학금을 수혜 받았습니다.

\section{VI. 인 용 문 헌}

1. Banerji, J., Sands, J., Strominger, J. L. and Spies, T. 1990. A gene pair from the human major histocompatibility complex encodes large prolinerich proteins with multiple repeated motifs and a single ubiquitin-like domain. Proc. Nat. Acad. Sci. 87:2374-2378. 
2. Blaskó, B., Széplaki, G., Varge, L., Ronai, Z., Prohászka, Z., Sasvari-Szekely, M., Visy, B., Farkas, H. and Füst, G. 2007. Relationship between copy number of genes (C4A, C4B) encoding the fourth component of complement and the clinical course of hereditary angioedema (HAE). Mol. Immunol. 44:2667-2674.

3. Balbi, G., Ferrera, F., Rizzi, M., Piccioli, P., Morabito, A., Cardamone, L., Ghio, M., Palmosano, G. L., Carrara, P., Pedemonte, S., Sessarego, M., De Angioletti, M., Notaro, R., Indiveri, F. and Pistillo, M. P. 2007. Association of $-318 \mathrm{C} / \mathrm{T}$ and $+49 \mathrm{~A} / \mathrm{G}$ cytotoxic $\mathrm{T}$ lymphocyte antigen-4 (CTLA-4) gene polymorphisms with a clinical subset of Italian patients with systemic sclerosis. Clin. Exp. Immunol. 149:40-47.

4. Cascalho, M. and Platt, J. L. 2001. The immunological barrier to xenotransplantation. Immunity 14:437-446.

5. Chardon, P., Renard, C. and Vaiman, M. 1999. The major hostocompatibility complex in swine. Immunol. Rev. 167:179-192.

6. Chen, F., Xie, J., Xhou, Y., Li, N. and Chou, K. Y. 2004. Novel SLA-DR alleles of three Chinese pig strains and the related function in human $\mathrm{T}$ cell response, Cell. Mol. Immunol. 1:212-21.

7. Geffrotin, C., Popescu, C. P., Cribiu, E. P., Boscher, J., Renard, C., Chardon, P. and Vaiman, M. 1984. Assignment of MHC in swine to chromosome 7 by in situ hybridization and serological typing. Ann. Genet. 27-213-219.

8. Hashimoto, M., Nakamura, N., Obayashi, H., Kimura, F., Moriwaki., A., Hasegawa, G., Shigeta, H., Kitagawa, Y., Nakano, K., Kondo, M., Ohta, M. and Nishimura, M. 1999. Genetic constributation of the BAT2 gene microsatellite polymorphism to the age-at-onset of insulin-dependent diabetes mellitus. Hum. Genet. 105:197-199.

9. Ierino, F. L., Gojo, S., Banerjee, P. T., Giovino, M., Xu, Y., Gere, J., Kaynor, C., Awwad, M., Monroy, R., Rembert, J., Hatch, T., Foley, A., Kozlowski, T., Yamada, K., Neethling, F. A.,
Fishman, J., Bailin, M., Spitzer, T. R., Cooper, D. K., Cosimi, A. B., LeGeurn, C. and Sachs, D. H. 1999. Transfer of swine major histocompatibility complex class II genes into autologous bone marrow cells of baboons for the induction of tolerance across xenogeneic barriers. Transplantation. 67:1119-1128.

10. Ittiprasert, W., Kantachuvesiri, S., Pavasuthipaisit, K., Verasertniyom, O., Chaomthum, L., Totemchokchyakarn, K. and Kitiyanant, Y. 2005. Complete deficiencies of complement $\mathrm{C} 4 \mathrm{~A}$ and $\mathrm{C} 4 \mathrm{~B}$ including 2-bp insertion in codon 1213 are genetiv risk factors of systemic lupus erythemaotosus in thai populations. J. Autoimmune. 25:77-9-84.

11. Lacerra, G., Musollino, G., Di Noce, F., Prezioso, R. and Carestia, C. 2007. Genotyping for known Mediterranean alpha-thalassemia point mutations using a multiplex amplification refractory mutation system. Haematologica. 92:254-255.

12. Lee, J. H., Simond, D., Hawthorne, W. J., Walters, S. N., Patel, A. T., Smith, D. M., O'Connell, P. J. and Moran, C. 2005. Characterization of the swine major histocompatibility complex alleles at eight loci in Westran pigs. Xenotransplantation 12:303-307.

13. Martens, G. W., Lunney, J. K., Baker, J. E. and Smith, D. M. 2003. Rapid assignment of swine leukocyte antigen haplotypes in pedigreed herds using a polymerase chain reaction-based assay. Immunogenetics 55:395-401.

14. Martinez, A., Salido, M., Bonilla, G., PascualSalcedo, D., Fernandez-Arquero, M., de Miguel, S., Balsa, A., de la Concha, E. G. and Fernandez-Gutierrez, B. 2004. Association of the major histocompatibility complex with response to infliximab therapy in rheumatoid arthritis patients. Arthritis Rheum. 50:1077-1082.

15. O'Connell, P. J., Hawthorne, W. J., Simond, D., Chapman, J. R., Chen, Y., Patel, A. T., Welters, S. N., Burgess, J., Weston, L., Stokes, R. A., Moran, C. and Allen, R. 2005. Genetic and functional evaluation of the level of inbreeding of 
the Westran pig; a herd with potential for use in xenotransplantation. Xenotransplantation. 12:308315.

16. Okamoto, K., Makino, S., Yoshikawa, Y., Takaki, A., Nagatsuka, Y., Ota, M., Tamiya, G., Kimura, A., Bahram, S. and Inoko, H. 2003. Identification of $I k B L$ as the second major histocompatibility complex-linked susceptibility locus for rheumatoid arthritis. Am. J. Hum. Genet. 72:303-312.

17. Renard, C., Hart, E., Sehra, H., Beasley, H., Coggill, P., Howe, K., Harrow, J., Gilbert, J., Sims, S., Rogers, J., Ando, A., Shigenari, A., Shiina, T., Inoko, H., Chardon, P. and Beck, S. 2006. The genomic sequence and analysis of the swine major histocompatibility complex. Genomics 88:96-110.

18. Robins, T., Bellanne-Chantelot, C., Barbaro, M., Cabrol, S., Wedell, A. and Lajic, S. 2007. Characterization of novel missense mutation in CYP21 causing congenital adrenal hyperplasia. J. Mol. Med. 85:247-255.

19. Rothbard, J. B. and Gefter, M. L. 1991. Interactions between immunogenic peptides and MHC proteins. Annu. Rev. Immunol. 9:527-565.

20. Sachs, D. H. 1994. The pig as a potential xenograft donor. pathol. Biol. 42:185-191.

21. Sachs, D. H., Leight, G., Cone, J., Schwarz, S., Stuart, L. and Rosenberg, S. 1976. Transplantation in miniature swine. I. Fixation of the major histocompatibility complex. Transplantation. 22: 559-567.

22. Schroeder, H. W., Zhu, Z. B., March, R. E., Campbell, R. D., Berney, S. M., Nedospasov, S. A., Turetskaya, R. L., Atkinson, T. P., Go, R. C., Cooper, M. D. and Volanakis, J. E. 1998. Susceptibility locus for IgA deficiency and common variable immunodeficiency in the HLADR3-B8-A1 haplotype. Mol. Med. 4:72-86.

23. Shichi, D., Kikkawa, E. F., Ota, M., Katsuyama,
Y., Kimura, A., Matsumori, A., Kulski, J. K., Naruse, T. K. and Inoko, H. 2005. The haplotype block, NFKBIL1 - ATP6V1G2 - BAT1 - MICB - MICA, within the class III class I boundary region of the human major histocompatibility complex may control susceptibility to hepatitis C virus-associated dilated cardiomyopathy. Tissue Antigens 66:200208.

24. Smith, D. M., Lunney, J. K., Martens, G. W., Ando, A., Lee, J. H., Ho, C. S., Schook, L., Renard, C. and Chardon, P. 2005. Nomenclature for factors of the SLA class-I system, 2004. Tissue Antigens 65:136-149.

25. Taylor, A., Tabrah, S., Wang, D., Sozen, M., Duxbury, M., Whittall, R., Humphries, S. E. and Norbury, G. 2007. Multiplex ARMS analysis to detect 13 common mutations in familial hypercholesterolaemia. Clin. Genet. 71:561-568.

26. Tsuda, T., Moriguchi, M., Asanuma, Y., Imamura, S., Toyoda, A., Yamada, S., Terai, C., Suzuki, K. and Tabei, K. 2007. C4B deficiency association with membranoproliferative glomerulonephritis. Intern. Med. 46:756-770.

27. Wu, Q., Xiong, P., Liu, J. Y., Feng, S. T., Gong, F. L. and Chen, S. 2004. The study of new SLA classical molecules in inbreeding Chinese Wuzhishan pig. Transplant. P. 36:2483-2484.

28. Xie, T., Rowen, L., Aguado, B., Ahearn, M. E., Madan, A., Qin, S., Campbell, R. D. and Hool. L. 2003. Analysis of the gene-dense major histocompatibility complex class III region and its comparison to mouse. Genome Res. 13:2621-2626.

29. Yang, Y., Lhotta, K., Chung, E. K., Eder, P., Neumair, F. and Yu, C. Y. 2004. Complete complement components $\mathrm{C} 4 \mathrm{~A}$ and $\mathrm{C} 4 \mathrm{~B}$ deficiencies in juman kidney diseases and systemiclupus erythematosus. J. Immunol. 173:2803- 2814.

(접수일자 : 2007. 8. 10. / 채택일자 : 2007. 10. 18.) 